\title{
A difusão de imaginários sociodiscursivos relacionados a gênero por intermédio das inferências na publicidade: uma proposta de análise semiolinguística
}

Raquel Monteiro de Rezende ${ }^{\mathrm{i}}$

Janayna Rocha da Silva ${ }^{\text {ii }}$

\begin{abstract}
RESUMO
O presente artigo pretende, sob a luz dos conceitos da Teoria Semiolinguística, fundada por Patrick Charaudeau, analisar como as inferências contidas no discurso publicitário contribuem para a difusão de imaginários sociodiscursivos. Após breve explanação teórica pertinente à análise, será examinado um corpus composto por quatro anúncios de perfumes de $\mathrm{O}$ Boticário voltados especificamente para os públicos feminino e masculino, sendo dois exemplares relativos a cada caso. A partir de tal análise, será observado quais imaginários concernentes às questões de gênero podem ser identificados em tais propagandas e como, consequentemente, a publicidade colabora com a manutenção dessas representações.
\end{abstract}

Palavras-chave: Publicidade; Discurso; Imaginários; Gênero.

\begin{abstract}
The present article intends, considering the concepts developed by the Semiolinguistic Theory, founded by Patrick Charaudeau, to analyze how the inferences contained in the advertising discourse contribute to the diffusion of sociodiscursive imaginaries. After a brief theoretical explanation pertinent to the analysis, four ads by the Brazilian company "O Boticário" specifically designed for the female and male audiences will be examined, two examples of which. It will be observed which imaginaries concerning gender issues can be identified in such advertisements and how, consequently, advertising collaborates with the maintenance of these representations.
\end{abstract}

Keywords: Advertising; Discourse; Imaginaries; Gender.

\footnotetext{
${ }^{i}$ Doutoranda em Estudos de Linguagem pela Universidade Federal Fluminense (UFF). ORCID: https://orcid.org/0000-0002-4004-6033 | raq.rezende@ gmail.com

ii Doutoranda em Estudos de Linguagem pela Univerisidade Federal Fluminense (UFF) e professora da Secretaria Municipal de Educação do município do Rio de Janeiro.

E-mail: rochajanayna1412@gmail.com
} 


\section{INTRODUÇÃO}

O anúncio publicitário, gênero formulado com a intenção de persuadir o consumidor, é parte significativa do cotidiano humano. Nos mais variados suportes disponíveis atualmente, as propagandas estão presentes com o claro intuito de convencer seu destinatário ao consumo. Ao contrário do que se pode acreditar, a publicidade não se vale apenas da mera exposição da qualidade de um determinado produto, sendo necessárias, para o sucesso do processo de convencimento do consumidor, táticas bem articuladas de manipulação. Tais táticas são majoritariamente baseadas em operações discursivas, que são minuciosamente planejadas para que o objetivo publicitário seja alcançado, sendo, então, a publicidade uma área de grande interesse dos estudos de linguagem.

Partindo do princípio de que a linguagem é utilizada, grosso modo, como um meio de manipulação interpessoal, Patrick Charaudeau (2016, p. 43), fundador da Teoria Semiolinguística, faz apontamentos que comprovam as condições psicossociais como imprescindíveis no que diz respeito à construção de sentido do discurso, visto que o "ato de linguagem" é definido como o resultado da ação de seres psicossociais através das atitudes do dizer e do fazer. Tais atitudes citadas pelo autor são intimamente ligadas às questões da publicidade e suas intenções, o que faz com que a Semiolinguística seja uma área de estudo que muito tem a contribuir com a compreensão das artimanhas de persuasão publicitária.

\footnotetext{
A noção de estratégia repousa na hipótese de que o sujeito comunicante (EUc) concebe, organiza e encena suas intenções de forma a produzir determinados efeitos - de persuasão ou de sedução - sobre o sujeito interpretante (TUi), para levá-lo a se identificar - de modo consciente ou não - com o sujeito destinatário ideal (TUd) construído por EUc. (CHARAUDEAU, 2016, p. 56)
}

A partir dos conceitos desenvolvidos pela teoria de Charaudeau, afirma-se que o anúncio publicitário é um tipo de contrato comunicativo, com estratégias discursivas que devem ser seguidas para que a comunicação se efetive. Assim sendo, a construção do anúncio publicitário como contrato perpassa, também, os conceitos dos sujeitos da linguagem, já que, sempre insistindo no caráter psicossociolinguageiro da comunicação, Charaudeau reafirma que, da necessidade de um novo olhar acerca dos fenômenos 
sociais da linguagem, derivou também a conveniência de se estudar os sujeitos que se comunicam, vistos, agora, como personagens sociais mais complexos.

Reforçando o conceito de que a linguagem é naturalmente ligada à ideologia, é possível também recorrer aos postulados de Bakhtin (2011), que já afirmava que toda e qualquer atividade humana acontece sob o fenômeno da comunicação, e a língua assim utilizada só pode ocorrer exclusivamente a partir de enunciados. $\mathrm{O}$ autor russo afirma que a enunciação é um fenômeno sócio-histórico, que não deve ser analisado individualmente e fora de contexto, tendo a linguagem também um caráter ideológico.

Em realidade, porém, toda informação semelhante dirige-se a alguém, é suscitada por alguma coisa, tem algum objetivo, ou seja, é um elo real na cadeia de comunicação discursiva em determinado campo de atividade humana ou da vida. (BAKHTIN, 2011, p. 288)

Isto posto, o anúncio publicitário, por ser um gênero específico, precisa ser analisado sob uma perspectiva social, contextualizado a partir do tempo e do espaço em que é produzido. Assim sendo, considerando-se tal viés, entende-se que o fenômeno da linguagem é intimamente ligado às questões pertinentes à sociedade dentro da qual é produzido, como as compreensões sociais sobre gênero. Em se tratando de publicidade, tais concepções são abordadas de maneira conveniente, de modo que o objetivo de influência seja atingido.

No ato de linguem de um discurso publicitário, pode-se dizer que é fabricada uma imagem de um TUd a quem falta algo; esse TUd "deve procurar preencher essa falta". Então, uma hipótese é criada por parte do EU publicitário, que supõe que o TUi se identificará com a imagem de TUd que foi proposta. (CHARAUDEAU, 2016, p. 46)

Desse modo, percebe-se que os anúncios publicitários partem de concepções sociais para apelar a um determinado público que se quer persuadir, táticas investigadas sob a luz da Teoria Semiolinguística quando se trata do estudo acerca dos sujeitos da linguagem.

\section{OS SUJEITOS DA LINGUAGEM}

Ao considerar o caráter sócio-histórico da linguagem, é inevitável que se avalie o papel dos sujeitos que participam da situação de comunicação. Se por muito tempo as 
teorias estruturalistas promoviam uma visão simplista acerca de tal circunstância, indicando locutores e interlocutores como meros emissores e receptores da linguagem, a Teoria Semiolinguística atualiza a compreensão até então vigente. Ao propor o desdobramento dos sujeitos do ato da linguagem em quatro, é, então, superada a perspectiva reducionista de dois sujeitos que, de maneira direta, se comunicam sem que condições extralinguísticas sejam observadas. Assim, além do explícito já exposto na superfície do ato de linguagem, o implícito passa a ter também suma importância no que diz respeito aos estudos do discurso.

Sob tal perspectiva, o ato de linguagem é, então, compreendido a partir da organização de dois pares de sujeitos que ocupam espaços distintos: os parceiros e os protagonistas. Os parceiros, EUc (sujeito comunicante) e TUi (sujeito interpretante), são os seres de "carne e osso", que habitam o espaço externo do ato. Enquanto o EUc é o ser social que assume o projeto do dizer, o TUi é o sujeito de função interpretativa. Porém, entre EUc e TUi, há os protagonistas do ato, que são EUe (sujeito enunciador) e TUd (sujeito destinatário), que podem ser considerados como seres de fala ou "de papel", submetidos às projeções do EUc.

Ao considerar o ato de linguagem como uma encenação, Charaudeau (2016, p. 75) aponta a necessidade de utilização de estratégias para que as intenções da comunicação sejam bem-sucedidas. Deste modo, ao planejar sua fala, EUc tem a necessidade de consciência de seu destinatário para que estratégias convenientes sejam traçadas a fim de satisfazê-lo. Portanto, considerando-se peculiaridades sociais e/ou individuais, faz-se necessária a idealização de um TUd, o sujeito que se quer atingir. É a partir de TUd que o projeto comunicativo de EUc é realizado, inclusive com a idealização de uma imagem favorável do enunciador. Deste modo, EUc, ao planejar sua fala, deve se utilizar de táticas a fim de projetar uma imagem de si que seja favorável quanto ao seu destinatário ideal. Daí surge o conceito de EUe, ser de fala projetado por EUc que se efetiva no projeto comunicativo. O seguinte esquema sintetiza o funcionamento de uma situação de comunicação. 
Figura 1: Representação do dispositivo da encenação da linguagem

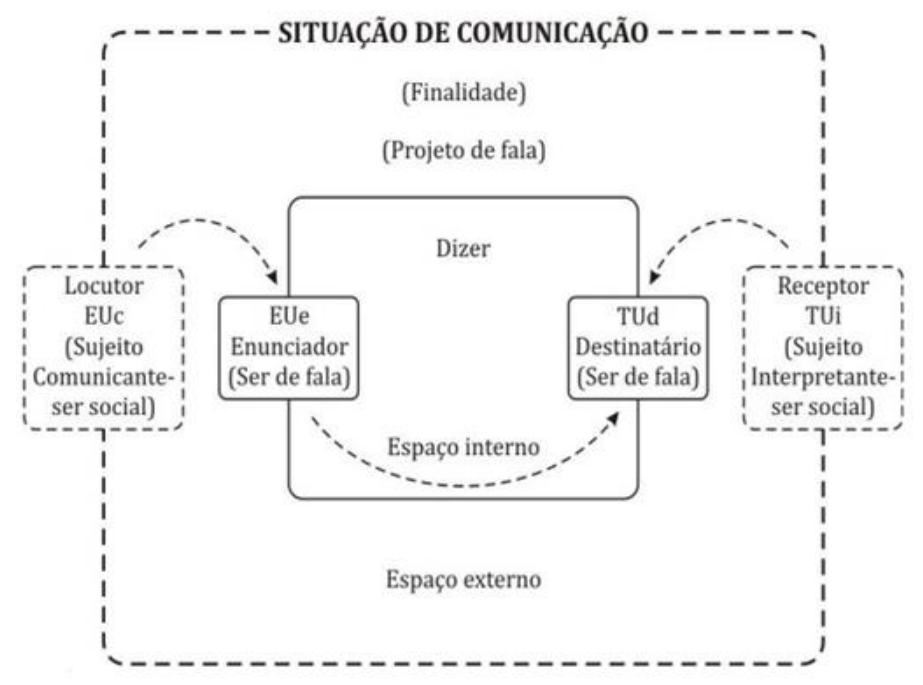

Fonte: CHARAUDEAU, 2016, p. 52.

Assim sendo, nota-se que tal organização proposta por Charaudeau muito tem a contribuir para a compreensão do funcionamento da publicidade, visto que, para ter sucesso, a persuasão publicitária deve ser planejada de modo que seja satisfatória a um público específico. Ou seja, a agência publicitária, no papel que EUc, precisa criar uma imagem do produto a ser divulgado, um EUe que seja sedutor ao perfil de consumidor que se quer alcançar, o TUd.

Usando como exemplo as propagandas de cosméticos, objeto de análise do presente artigo, nota-se que produtos distintos, destinados a públicos determinados que variam de acordo com questões de gênero, idade e poder aquisitivo, resultam em peças publicitárias específicas, visto que cada grupo apresenta suas características próprias. Tais peculiaridades são, então, consideradas e as estratégias comunicativas das campanhas são desenvolvidas a fim de que o público-alvo seja alcançado.

O exemplo abaixo trata de uma peça publicitária desenvolvida para a linha "Mamãe e Bebê", da marca de cosméticos Natura. O produto, por ter um público-alvo específico, mães e seus bebês, torna necessário que a campanha dialogue diretamente com o potencial consumidor em questão, estabelecendo assim um TUd. Logo, percebese que, ao contrário do que é comum em propagandas de cosméticos, geralmente 
voltadas para jovens adultos e adultos, não há nos anúncios de "Mamãe e Bebê" o apelo à sensualização de corpos ou a aspectos próprios da beleza física.

Figura 2: Linha Mamãe e Bebê

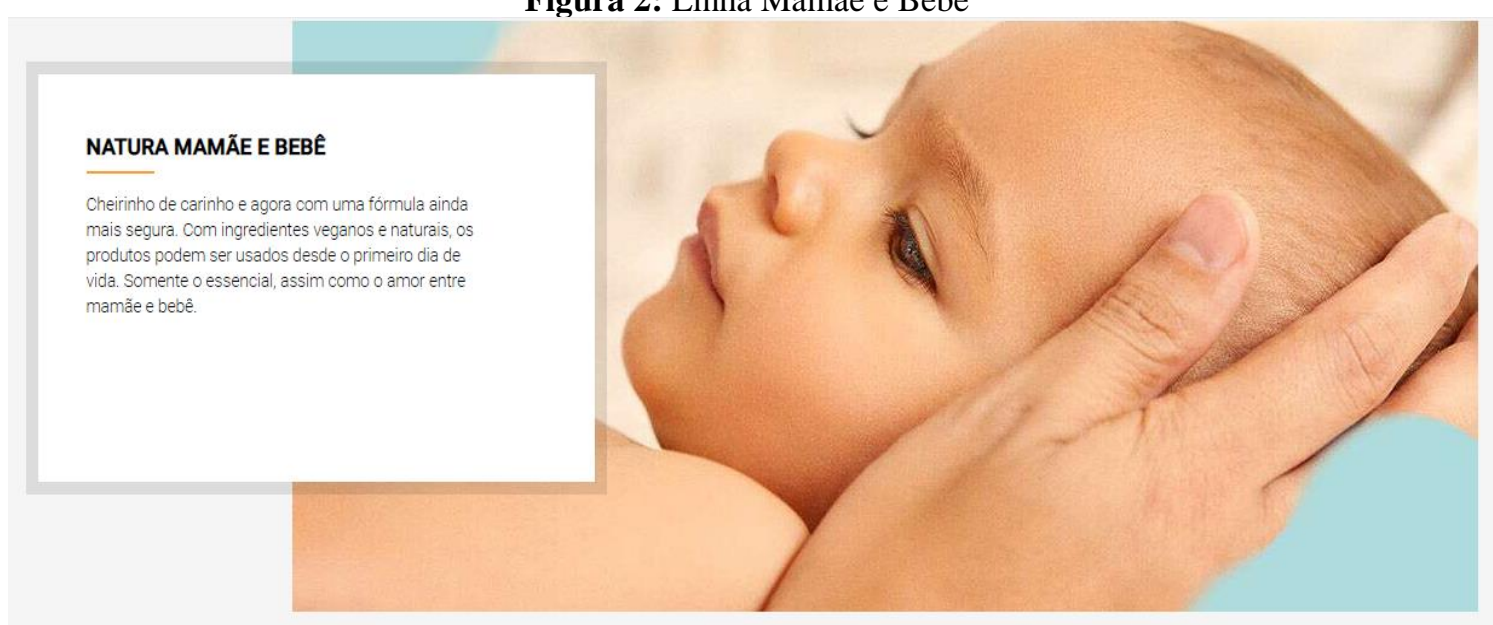

Disponível em: < https://www.natura.com.br/mamae-e-bebe> Acesso em: 19 jan. 2021.

É necessário ressaltar que, tendo em vista o TUd definido, mães e seus bebês, a agência publicitária, na condição de EUc, se utiliza de estratégias para persuadir o público em questão à compra do produto. O substantivo "cheirinho", por exemplo, é utilizado no diminutivo a fim de promover um efeito de sentido que remeta ao afeto, ao amor da mãe por seu bebê. Ademais, o anúncio qualifica a forma utilizada na produção da linha "Mamãe e Bebê" como "ainda mais segura" e passível de ser utilizada "desde o primeiro dia de vida". O anúncio busca promover a confiança do consumidor em relação ao produto veiculado. Há, também, por intermédio do uso de cores suaves, uma comunicação visual que remete à afetividade. Além disso, há na imagem a presença de uma mão que acaricia o bebê ao mesmo tempo em que a criança olha em direção a alguém. Embora o rosto de quem acaricia não apareça enquadrado na imagem, é possível inferir que se trata da mãe em um momento de afeto com o seu bebê.

Tendo em vista a organização dos sujeitos da linguagem proposta pela Teoria Semiolinguística, nota-se, então, que é da projeção que EUc faz de TUd que depende majoritariamente o sucesso da comunicação. Se tal expectativa se mostrar propícia, maiores serão as chances de que TUi, o sujeito "de carne e osso", coincida com TUd, o sujeito idealizado, proporcionando, assim, o triunfo do projeto comunicativo de EUc. 
Desse modo, devido à sua grande relevância já assinalada, torna-se pertinente que se examine de maneira mais detalhada como se desenvolvem as projeções acerca de TUd. No que se refere às campanhas publicitárias, muitas vezes o destinatário é percebido como um sujeito estereotipado e previsível, que tem as suas necessidades já calculadas pelas empresas de publicidade. Daí, então, surge a inevitabilidade de se discorrer sobre outro conceito caro aos estudos de linguagem desenvolvido pela Teoria Semiolinguística: os imaginários sociodiscursivos.

\section{IMAGINÁRIOS SOCIODISCURSIVOS}

Da necessidade de se debater sobre questões pertinentes aos estereótipos, surgiram muitos estudos relacionados às questões das representações. O primeiro conceito, o de representação coletiva, surge com Émile Durkheim. A partir de tal definição, o sociólogo francês discorre sobre saberes comuns aos grupos sociais que resultam em comportamentos e compreensões coletivas padronizadas. Posteriormente, Serge Moscovici retoma o conceito sociológico de Durkheim e o aproxima mais da psicologia social, seu campo de estudo. Daí desponta a concepção de representação social, que, diferente do que ocorre com o conceito de representação coletiva, dá conta de assimilações mais heterogêneas que são compartilhadas socialmente em forma de opiniões.

Ao ponderar sobre as representações sociais, Charaudeau (2015) afirma que estas são estruturadas por saberes de conhecimento e saberes de crença. Enquanto no primeiro caso ocorre uma compreensão geral baseada em um pensamento científico que possa explicar o funcionamento do mundo, no segundo, encontra-se uma consciência de caráter axiológico muito mais ligado às práticas de julgamento social e pobre de avaliação técnica.

A partir do engendramento de tais tipos de saberes, emergem as representações, utilizadas pelos sujeitos como um meio de compreensão da realidade do mundo. Assim sendo, entende-se que somos cercados por um compósito de realidades brutas que precisam ser apreendidas. Essas apreensões são, então, feitas a partir da racionalidade humana, que utiliza as representações sociais como intermédio para tal. Assim, 
baseando-se em seus saberes, o homem significa a realidade do mundo transformando-a em algo real.

Já da definição de representação social, desenvolve-se o conceito de imaginários. Segundo Charaudeau (2015, p. 205), tal movimento ocorre por intermédio de uma dupla interação: do sujeito com a realidade e do sujeito com seus semelhantes. Assim, a partir de uma simbolização racional e afetiva, o mundo passa a ser significado, sendo tal significação sedimentada na memória coletiva. Uma vez que os imaginários surgem da interação dos sujeitos que ocupam o mesmo espaço e se manifestam pela linguagem, ergue-se o conceito de imaginário sociodiscursivo.

\footnotetext{
À medida que esses saberes, enquanto representações sociais, constroem o real como universo de significação, segundo o princípio de coerência, falaremos de "imaginários". E tendo em vista que estes são identificados por enunciados linguageiros produzidos de diferentes formas, mas semanticamente reagrupáveis, nós os chamaremos de "imaginários discursivos". Enfim, considerando que circulam no interior de um grupo social, instituindo-se em normas de referências por seus membros, falaremos de 'imaginários sociodiscursivos'. (Charaudeau, 2015, p. 203)
}

É importante ressaltar que os conceitos de representação social e imaginário aqui apresentados são bastante pertinentes no que diz respeito à análise da publicidade. Uma vez que a atividade publicitária apresenta como objetivo principal a persuasão de um TUd à aquisição de um determinado produto ou à adesão a um comportamento específico, é de suma importância que o EUc, responsável por engatilhar o ato de comunicação, tenha consciência da representação do sujeito que se deseja alcançar (TUd). Como já afirmado anteriormente, ao se discorrer sobre os sujeitos da linguagem, sem que se tenha uma projeção coerente do interlocutor que se deseja atingir, a comunicação é fadada ao fracasso. No caso específico das peças publicitárias, tal projeção se dá majoritariamente a partir da exploração dos imaginários.

\section{PROCESSO DE SEMIOTIZAÇÃO E EMERGÊNCIA DE IMAGINÁRIOS}

Conforme já discutido, os imaginários surgem da necessidade humana de assimilação da realidade do mundo, a fim de que esta realidade seja, portanto, formatada 
até que sejam alcançados valores de verdade, do real. Assim sendo, é necessário, então, que se dê a devida atenção ao processo que a Teoria Semiolinguística denomina como semiotização (CHARAUDEAU, 2018, p.41), que se divide em dois estágios: transformação e transação.

Enquanto o processo de transformação dá conta, resumidamente, de designar tudo o que existe e ocorre no mundo, são os princípios do processo de transação que permitem que esse mundo já designado sirva como um objeto de troca entre os sujeitos que se comunicam. A transformação consiste em quatro processos: identificação, que nomeia o mundo e tudo que nele existe; qualificação, que tem a função de descrever e caracterizar; ação, que possibilita a impressão de uma identidade narrativa aos seres do mundo; e causação, que especifica as relações de causalidade das ações sofridas ou conduzidas pelos seres.

Já a transação é constituída pelos quatro seguintes princípios: alteridade, que considera que a comunicação se efetiva entre dois ou mais sujeitos que compartilham semelhanças e dissemelhanças; pertinência, uma vez que um ato de linguagem só é bem-sucedido se houver adequação ao contexto comunicativo; influência, pois o objetivo primordial da linguagem é a influência de um indivíduo sobre outro; e, por fim, a regulação, que dá conta das estratégias e restrições que devem ser adotadas para o triunfo da influência. Ainda de acordo com os postulados da Teoria Semiolinguística, transformação e transação são processos que se articulam de maneira solidária, sendo o primeiro estabelecido pela atuação do segundo, como mostra o esquema a seguir:

Figura 3: Duplo processo de semiotização

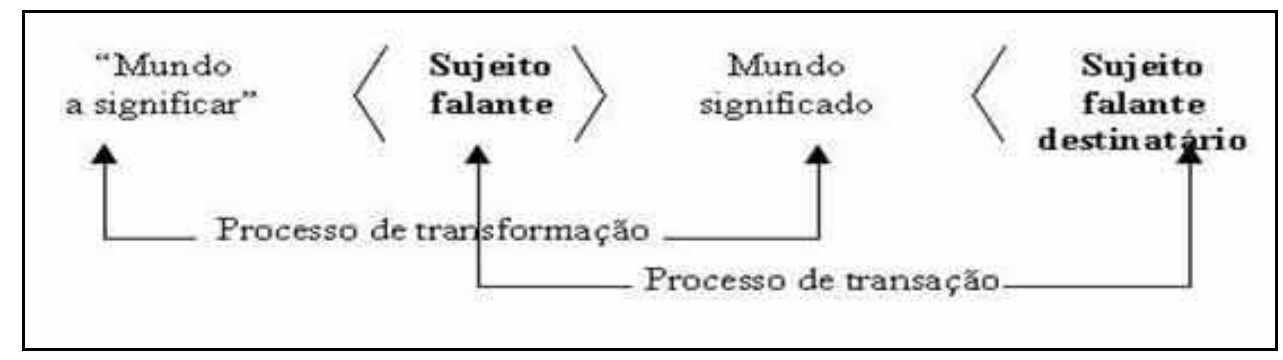

Fonte: CHARAUDEAU, 2007, p. 17.

Ao postular sobre a formatação da realidade crua de um mundo incompreendido em um mundo significado e consequentemente "real", Charaudeau (2017) afirma que tal movimento ocorre, basicamente, através do processo de transformação: 


\begin{abstract}
'o real' refere-se ao mundo tal qual ele é construído e estruturado por atividade significante do homem por meio do exercício da linguagem em suas diversas operações de nominação dos seres do mundo, de caracterização de suas propriedades, de descrição de suas ações inseridas no tempo e no espaço e de explicação da causalidade dessas ações. (CHARAUDEAU, 2017, p. 574)
\end{abstract}

O autor (2015) declara que é a partir desse movimento de designação engrenado pelo duplo processo de semiotização que se desenvolvem também os imaginários, que auxiliam em uma compreensão social do mundo.

A significação da realidade procede de uma dupla relação: a relação que o homem mantém com a realidade por meio de sua experiência, e a que estabelece com os outros para alcançar o consenso de significação. A realidade tem, portanto, necessidade de ser percebida pelo homem para significar, e é essa atividade de percepção significante que produz os imaginários, os quais em contrapartida dão sentido a essa realidade. (CHARAUDEAU, 2015, p. 203)

Assim, compreende-se que é a partir desse mundo significado pela linguagem que a comunicação humana se torna possível. Entretanto, deve-se ressaltar que nem sempre as trocas comunicativas se efetivam de maneira transparente, podendo ocorrer também por intermédio de inferências.

\title{
4. A CIRCULAÇÃO DE IMAGINÁRIOS SOCIODISCURSIVOS POR INTERMÉDIO DAS INFERÊNCIAS
}

Segundo Dell’Isola (2001), “a inferência não está no texto, é uma operação que os leitores desenvolvem enquanto estão lendo o texto ou após terem completado sua leitura." (DELL'ISOLA, 2001, p. 42). Assim sendo, entende-se que parte do sentido contido nas trocas comunicativas não é explícito e só pode ser obtido por processos inferenciais. Desse modo, são reforçadas as observações de Charaudeau de que os imaginários circulam também de modo inconsciente, uma vez que, muitas vezes, mesmo que haja um planejamento por parte de EUc, nem sempre TUd terá a clara percepção dos implícitos que reforçam determinadas representações e irá recebê-los de modo passivo.

Ao discorrer sobre memória e processos inferenciais, Minsky (1974) desenvolve os conceitos de frames, schemas, scripts e plans, muito utilizados por pesquisadores da 
linguagem em busca de compreensões sobre cognitivismo, leitura e interpretação. Porém, no que diz respeito à análise da emergência de imaginários, é pertinente que se dê maior atenção à definição de frames, que são traços semânticos que remetem a uma noção maior já estabelecida. É o que ocorre, por exemplo, com os termos "freio", "pneu” e "embreagem", que nos reportam ao frame "automóvel”. Tal teoria auxiliará no trabalho de análise contido no presente trabalho que, conforme será exposto a seguir, se utilizará dos conceitos da Teoria Semiolinguística como base de investigação.

\section{METODOLOGIA}

Postos os conceitos até agora apresentados, torna-se pertinente que se analisem quais entradas podem ser identificadas como desencadeadoras dos frames de homem e mulher nos enunciados que compõem o corpus disponível. Desse modo, será possível notar, a partir do reconhecimento de tais traços semânticos e seus respectivos frames desencadeados, como a feminilidade e a masculinidade são representadas em anúncios de cosméticos destinados para gêneros específicos. Assim, será observado como os imaginários de homem e mulher brasileiros de poder aquisitivo médio circulam na sociedade a partir dos conceitos que a marca $\mathrm{O}$ Boticário fornece de seus produtos indicados para o público feminino e masculino.

Considerando-se os processos de identificação e qualificação, desenvolvidos por Charaudeau e já apresentados em seção anterior, será realizada a análise de palavras que tenham como referência o produto ou o público ao qual o mesmo é destinado homem/mulher. Assim, o exame dos anúncios de Malbec, Quasar, Glamour Love Me e Floratta Rose indicarão como inferências em anúncios publicitários contribuem para o reforço de imaginários sociodiscursivos acerca dos gêneros masculino e feminino no Brasil.

É importante que se esclareça que a escolha dos anúncios foi feita pela consideração dos produtos que constam no site oficial da empresa como os mais vendidos da marca. Apesar de O Boticário comercializar itens diversos relacionados ao bem-estar pessoal, é notório que suas linhas de perfumaria são os artigos mais populares da empresa, o que torna oportuno que os anúncios de tais produtos sejam os eleitos para a constituição do corpus em apreço. 
Uma simples consulta ao site de O Boticário indica que dois dos três perfumes masculinos mais vendidos pela empresa no mês de dezembro de 2020 foram Malbec e Quasar, enquanto as linhas Glamour e Floratta figuraram entre os líderes de venda no segmento feminino.

\section{MOVIMENTOS DE ANÁLISE}

Antes de iniciar a análise efetiva dos anúncios, é relevante que se considerem os nomes dos produtos em apreço. No que diz respeito aos itens indicados para o público masculino, deve-se notar que enquanto Quasar se refere à abreviação de quasi-stellar, um corpo celeste dotado de grande energia e luz intensa, Malbec alude a um tipo de vinho muito apreciado e reconhecido por sua boa qualidade. É importante que se leve em conta que tais nomes, que reportam o consumidor a uma concepção de força e requinte, já indicam o imaginário acerca do TUd em questão, o homem de classe média consumidor dos produtos da marca.

Já os perfumes femininos, cujos anúncios também servirão como corpus, são denominados Glamour Love Me e Floratta Rose, nomes que remetem, respectivamente, ao amor e às flores. Desta forma, percebe-se que, assim como ocorre com os produtos voltados para o público masculino, os nomes dos perfumes femininos em questão também são indicativos de um imaginário corrente de mulher sedutora e delicada. Assim, já a partir da denominação dos produtos em destaque, pode-se notar o indicativo de que, ao desenvolver suas mercadorias, O Boticário idealiza seu TUd a partir dos imaginários que circulam na sociedade referentes a masculinidade e feminilidade.

A análise dos textos de apresentação de Quasar, Malbec, Glamour Love Me e Floratta Rose, que constam no site de O Boticário, mostra a reafirmação de tais imaginários por parte da marca, como se vê nas descrições a seguir, transcritas do site oficial da marca.

Quadro 1: Descrição de Malbec

Malbec é uma fragrância masculina da família das Amadeiradas. É única e desenvolvida através de um processo de fabricação exclusivo no mundo.

Esse best seller foi o primeiro da linha Malbec, trazendo a inspiração do mundo dos 
vinhos para a perfumaria masculina. O álcool vínico, obtido através da fermentação da uva, é envelhecido em barris de carvalho francês, iguais àqueles em que descansam os melhores vinhos do mundo.

Feito de notas frescas e amadeiradas com base de Ameixa, Carvalho e Baunilha, Malbec Desodorante Colônia representa a masculinidade de forma única. Combina com homens que sabem se impor. Que são notados por onde passam. Que têm a essência da conquista em tudo o que fazem.

Notas amadeiradas quentes se combinam ao frescor frutal a nuances especiadas, dando origem a uma fragrância masculina inesquecível, mais seca e menos adocicada, marca registrada de Malbec.

Disponível em: < https://www.boticario.com.br/malbec-desodorante-colonia-100-ml/> Acesso em 07 jan. 2021.

Quadro 2: Análise do anúncio de Malbec

\begin{tabular}{|l|l|}
\hline Identificação & Masculinidade, álcool, vinhos, conquista \\
\hline Qualificação & $\begin{array}{l}\text { Homens que sabem se impor, homens que são notados por onde } \\
\text { passam, homens que têm a essência da conquista em tudo que } \\
\text { fazem, inesquecível, fragrância mais seca, fragrância menos } \\
\text { adocicada. }\end{array}$
\end{tabular}

No anúncio de Malbec, os termos que se referem ao produto ou ao seu públicoalvo, o homem de classe média, indicam a masculinidade como algo ligado a um ideal de domínio. Percebe-se no texto em questão a alusão a um homem dominador e grandioso, que "sabe se impor", "é notado por onde passa" e "tem a essência da conquista".

É importante salientar que o termo "conquista" não se refere apenas à sedução amorosa, mas à "conquista em tudo o que fazem", excluindo, assim, um ideal de um sujeito ligado ao romantismo.

Como será exposto a seguir, veremos que a propaganda de Quasar se utiliza de uma compreensão equivalente dos valores masculinos.

Quadro 3: Descrição do perfume Quasar

Quasar Desodorante Colônia é uma fragrância masculina perfeita para homens que 
gostam de estar de bem com a vida e de sentir a sensação de energia e vitalidade.

Sendo da família Fougère Fresca, suas notas de saída passam uma sensação de grama molhada que contrasta com a combinação refrescante que vem de um Blend Cítrico de Cardamomo, Neroli, Mandarina, Limão e Bergamota. As notas de Cardamomo e Neroli dão uma certa picância e um ar fresh para a fragrância, e o Cedro Alaska presente em sua base dá aquele toque sútil amadeirado que muita gente gosta.

A vibração do homem que vive em ritmo pulsante é estimulada pelas notas amadeiradas do Cedro Alaska e Sândalo. Com perfumação prolongada bem evidente, Quasar Desodorante Colônia pode ser usado para prática de esportes, trabalho e é indicado especialmente para dias quentes.

A embalagem moderna na perfumaria masculina possui um novo formato que facilita a aplicação.

Quasar é uma fragrância masculina fresca, cheia de energia, para homens que buscam enfrentar seus medos e se superar sempre.

Disponível em: < https://www.boticario.com.br/quasar-desodorante-colonia-100ml/> Acesso em 07 jan. 2021.

Quadro 4: Análise do anúncio de Quasar

\begin{tabular}{|l|l|}
\hline Identificação & Energia (2x), vitalidade, vibração, prática de esportes, trabalho \\
\hline Qualificação & Fragrância masculina, refrescante, homens que gostam de estar de \\
& $\begin{array}{l}\text { bem com a vida, homem que vive em ritmo pulsante, fragrância } \\
\text { fresca e cheia de energia, homens que buscam enfrentar seus medos } \\
\text { e se superar sempre }\end{array}$ \\
\hline
\end{tabular}

O conceito atribuído ao perfume Quasar não é exatamente o mesmo de Malbec, mas explora outros traços de um imaginário recorrente acerca do que é ser "homem". Os termos "energia", "vitalidade" e "vibração" remetem à ideia de vigor, referindo-se, assim, a uma representação da masculinidade intensa e energética, formadora de sujeitos "que vivem em ritmo pulsante", que "enfrentam seus medos" e, assim, "se superam".

Assim sendo, a análise dos anúncios e dos quadros acima indica a difusão de um imaginário sociodiscursivo muito bem definido acerca do homem brasileiro de classe média. Como já afirmado anteriormente, orações adjetivas como "que sabem se impor", 
"que marcam" e "que enfrentam seus medos e se superam" reforçam o ideal de força e poder associados à masculinidade. Assim sendo, observa-se que o frame "homem" promovido pela empresa O Boticário é composto por traços semânticos diretamente ligados a questões de poder, confiança, coragem e determinação.

Considerando-se agora o processo de transação, é possível afirmar que no que diz respeito à análise proposta no presente trabalho, o princípio da influência é o que mais se mostra relevante, uma vez que o objetivo principal da publicidade é o da persuasão à compra. Tal indução ocorre pelo convencimento de que o consumidor (TUd), para se adequar a um determinado padrão, deve adquirir um determinado produto. Daí surge a importância da exploração dos imaginários por parte das empresas de publicidade.

Portanto, nota-se que no caso dos perfumes masculinos de O Boticário, a persuasão se dá através da exploração dos imaginários de masculinidade. Por meio de uma abordagem alocutiva, o anúncio induz TUd à compra recorrendo a uma promessa de encaixe social. Há o trato de que a aquisição dos produtos transformará o consumidor em um homem socialmente ideal: forte, determinado, dominador e vencedor. Isto é, são utilizadas inferências para reafirmar a adequação a determinadas representações. Assim sendo, ocorre a difusão e a consequente manutenção de um imaginário.

Quanto à análise dos anúncios dos perfumes femininos, percebe-se a mesma estratégia de campanha. Como esperado, as campanhas recorrem novamente à exploração de imaginários a fim de que a potencial consumidora se identifique no perfil projetado pela empresa e adquira o produto destacado para que possa se encaixar em um determinado padrão.

O exame das descrições oferecidas no site de O Boticário dos perfumes Glamour Love Me e Floratta Rose torna claro que as inferências relacionadas à feminilidade ratificam o imaginário comum de mulher, perpetuando-o socialmente.

Quadro 5: Descrição do perfume Glamour Love Me

Glamour Love Me é uma fragrância feminina envolvente que revela de forma delicada uma essência naturalmente sensual da mulher.

Através de suas notas, consegue transmitir a sensualidade natural que há na pele da mulher. E, para isso, ela usa a combinação da delicadeza das Pétalas de Rosa com a 
cremosidade da Baunilha, uma composição superfeminina e elegante que é revestida por uma embalagem tão delicada quanto a própria fragrância.

Disponível em: < https://www.boticario.com.br/glamour-love-me-desodorante-colonia-75ml/> Acesso em 9 jan. 2021.

Quadro 6: Análise do anúncio de Glamour Love Me

\begin{tabular}{|l|l|}
\hline Identificação & Sensualidade, delicadeza \\
\hline Qualificação & Feminina, envolvente, delicada (2x), naturalmente sensual, elegante \\
\hline
\end{tabular}

A análise das palavras-chave encontradas na descrição de Glamour Love Me denota a ativação de um frame específico no que diz respeito à concepção de mulher. Ao contrário do tom de seriedade, força e determinação que se encontra nos anúncios dos perfumes masculinos, aqui se percebem movimentos de identificação e qualificação destinados às mulheres que as reconhecem como sujeitos concernentes à delicadeza e à beleza, que, através do atributo da "sensualidade natural", se tornam "femininas", "delicadas" e "envolventes".

Daí, assim como também será notado no anúncio de Floratta Rose, já se vê que os imaginários de "homem" e "mulher" apresentados pelas descrições dos produtos de O Boticário são, além de distintos, bastante marcados.

Quadro 7: Descrição do perfume Floratta Rose

O Floratta Rose Desodorante Colônia possui uma fragrância tão inconfundível quanto frescor das flores. Ela traduz a beleza de uma mulher contemporânea, mas ao mesmo tempo romântica que acredita na força transformadora do amor. O perfume e encanto das flores fazem parte de Floratta Gold Desodorante Spray, uma fragrância inspirada pela alegria, amor e suavidade. Sua essência expressa uma mulher de personalidade irradiante e transformadora.

Disponível em: < https://www.boticario.com.br/combo-floratta-rose-desodorante-colonia-75mldesodorante-antitranspirante-body-spray-75g/> Acesso em 09 jan. 2021.

Quadro 8: Análise do anúncio de Floratta Rose

\begin{tabular}{|l|l|}
\hline Identificação & $\begin{array}{l}\text { Frescor, flores }(2 \mathrm{x}) \text {, beleza, mulher, encanto, alegria, amor, } \\
\text { suavidade. }\end{array}$ \\
\hline Qualificação & Contemporânea, romântica, que acredita força transformadora do \\
\hline
\end{tabular}


amor, personalidade irradiante.

A análise do conceito do perfume Floratta Rose apresentado no site de $\mathrm{O}$ Boticário, indica um imaginário pouco surpreendente a respeito da feminilidade. Palavras como "frescor", "encanto", “alegria", "amor", e "suavidade" denotam o padrão de amabilidade e doçura esperado das mulheres. É relevante então que se destaque que enquanto os anúncios de Malbec e Quasar endossam o ideal de força e poder relacionado ao gênero masculino, os traços semânticos contidos no texto de Floratta Rose evidenciam a mulher de maneira exatamente contrária, como uma figura doce e delicada. Tal noção de delicadeza é, aliás, reforçada pela referência feita às flores, que além de serem citadas na descrição do produto servem de inspiração para o nome da linha, remetendo, assim, à potencial consumidora a uma compreensão de graciosidade que se espera das mulheres.

Mais uma vez, assim como ocorre na propaganda de Glamour Love Me, a mulher também é identificada e qualificada como um ser ligado à boa aparência física e ao amor romântico, fato que se percebe pela menção aos substantivos "beleza", "amor" e "romântica".

Outra observação que merece destaque é a presença do substantivo "força". Como já afirmado anteriormente, diferentemente do que ocorre nos anúncios já analisados voltados para o público masculino, as propagandas de Glamour Love Me e Floratta Rose não qualificam a mulher como alguém forte. Assim, é pertinente apontar que enquanto Malbec enaltece "homens que sabem se impor" e Quasar cita "uma explosão de energia para o homem determinado", o anúncio de Floratta Rose associa a força feminina a um impulso sentimental e romântico, a "força transformadora do amor".

Após análise particular da descrição de cada um dos produtos em apreço, é oportuno que se faça a comparação geral dos anúncios, dividindo-os em dois grupos: textos voltados para o público feminino e textos voltados para o público masculino. Assim, será possível que se tenha uma visão mais ampla dos imaginários sociodiscursivos de gêneros presentes em tais peças.

O estudo dos quadros relativos aos processos de transformação contidos nos textos de descrição de Malbec, Quasar, Glamour Love Me e Floratta Rose identifica, 
pelo uso de substantivos, homens como sujeitos relacionados ao álcool, à energia, à vitalidade, ao desafio e à paixão por conquistas. Por outro lado, a identificação da mulher é composta pelos traços de doçura, sensualidade, delicadeza, beleza e pela crença na força do amor. Já a análise do processo de qualificação, que se dá por intermédio do uso de adjetivos, avalia o homem ideal, imagem utilizada para persuadir TUd, como único, instigante, notado, pulsante, determinado e destemido, ao passo que a feminilidade é caracterizada como bela, delicada, sensual, romântica e elegante.

É pertinente ressaltar que tais observações corroboram as afirmações de Pierre Bourdieu, que ao discorrer sobre a dominação masculina, descreve-a como um processo velado de imposição de poder que se instala implicitamente através das relações sociais. Bourdieu sustenta que tal imposição da superioridade masculina, mesmo ocorrendo de maneira dissimulada, estimula a manutenção de um imaginário masculino ligado à força e à virilidade, em oposição ao imaginário constante de fragilidade da mulher.

Delas se espera que sejam "femininas", isto é, sorridentes, simpáticas, atenciosas, submissas, discretas, contidas ou até mesmo apagadas. E pretensa "feminilidade" muitas vezes não é mais que uma forma de aquiescência em relação às expectativas masculinas, reais ou supostas, principalmente em termo de engrandecimento do ego. (BOURDIEU, 2018, p. 96)

Isto posto, atesta-se a que os frames de homem e mulher que constam nas descrições de O Boticário são caracterizados de maneira muito distinta e específica, perpetuando-se, assim, por intermédio de inferências, imaginários sociodiscursivos que ainda reafirmam o ideal de força e a vitalidade da masculinidade em oposição à delicadeza e ao romantismo feminino. É ratificado também o princípio de que a mulher deve ser fisicamente atraente, preocupação pouco relevante para o público masculino, já que a menção aos termos "beleza" e "sensualidade" se encontram apenas nas descrições de Glamour Love Me e Floratta Rose.

\section{IMAGINÁRIOS E CONFIGURAÇÃO SOCIAL}

Conforme se observou no trabalho de análise, os frames de homem e mulher identificados a partir das descrições dos produtos Malbec, Quasar, Glamour Love Me e Floratta Rose apresentam representações nítidas acerca da feminilidade e da 
masculinidade. Sabendo-se que a publicidade estimula o consumo por meio de uma proposta de TUe a TUd da concessão de um atributo em troca da aquisição de um produto, constata-se, portanto, que os textos publicitários aqui analisados incitam o consumidor (TUd) a adquirir os produtos de O Boticário por intermédio da propagação de imaginários de gênero. Desse modo, TUd, na condição homem ou mulher, receberá as virtudes socialmente esperadas de seu gênero ao obter os produtos disponibilizados para si. Porém, não se pode esquecer que, efetivamente, tais virtudes são frutos de imaginários que circulam socialmente e que, como se pode ver nos casos aqui apresentados, são difundidos através do discurso.

É pertinente se ressaltar que, por limitações óbvias de espaço, no presente trabalho não seria possível a análise de um maior número de anúncios dos produtos disponíveis no portfólio de O Boticário. Porém, visando a consistência da exposição dos resultados obtidos, deve-se considerar que, durante a fase de levantamento de corpus, foi possível notar que os anúncios de alguns outros perfumes da seção masculina, mesmo que em minoria, ainda oferecem outro tipo de compreensão da masculinidade, como são os casos de Portinari, que apela para o ideal da inteligência, e Arbo, que explora o perfil de homem livre e aventureiro. Já no que diz respeito ao que se pôde perceber da exposição de outros produtos da perfumaria feminina, é ínfima a quantidade de anúncios que, ao se referirem diretamente ao público-alvo (TUd), se afastam do apelo a beleza e delicadeza.

Assim sendo, não se pode deixar de observar que, apesar de comercializar uma enorme variedade de mercadorias, no que diz respeito à publicidade, a marca $\mathrm{O}$ Boticário parece essencialmente segmentar sua vasta gama de produtos em apenas dois nichos: feminino e masculino. Desse modo, obtém-se uma falsa impressão de possibilidades, uma vez que homens e mulheres são induzidos a acreditar que, dentre tantos itens, há a viabilidade de escolha de um produto cujo conceito encaixe em seu perfil. Porém, a observação dos imaginários sociodiscursivos que comparecem nos anúncios analisados aponta que a variedade de produtos não contempla necessariamente uma variedade de perfis de homens e mulheres, já que os mesmos são classificados sob perspectivas engessadas de feminilidade e masculinidade.

Torna-se, por consequência, inevitável considerar que, através da difusão de tais imaginários, a publicidade se apresente como reflexo da sociedade na qual é veiculada. 
Ao postular sobre imaginários sociodiscursivos, Charaudeau afirma que um julgamento não é absolutamente verdadeiro no que diz respeito a quem é julgado, mas muito esclarecedor sobre quem julga. "Todo julgamento acerca do outro é ao mesmo tempo revelador de si mesmo: diz, talvez, algo torpe sobre outro (refração), mas diz, ao mesmo tempo, algo de verdadeiro sobre aquele que pronuncia o julgamento (reflexão)." (CHARAUDEAU, 2017, p. 573)

Desse modo, de acordo com as afirmações do autor, pode-se compreender que os resultados encontrados na análise exposta no presente trabalho denotam uma sociedade de viés sexista, que ao mesmo tempo em que promove força e vitalidade como atributos masculinos, difunde beleza e delicadeza como traços femininos, evidenciando, portanto, a perspectiva de uma sociedade patriarcal que naturaliza a crença da superioridade masculina. Nota-se também que assim ocorre a promoção de uma ideologia por intermédio de implícitos, visto que os valores de masculinidade e feminilidade propagados por tais anúncios não se apresentam de maneira direta. Pelo contrário, como já afirmado anteriormente, a grande disponibilidade de itens propicia até mesmo uma falsa impressão de variadas possibilidades quanto às identificações de gênero. Assim, como afirma Van Dijk (2008), as mentes são premeditadamente controladas pelo discurso para que haja a manutenção de certas organizações sociais dominantes.

\footnotetext{
Os grupos ou classes dominantes tendem a esconder sua ideologia (e, portanto, seus interesses) e terão por meta fazer que esta seja, em geral, aceita como um sistema de valores, normas e objetivos "geral" ou "natural". Nesse caso, a reprodução ideológica incorpora a natureza da formação de consenso, e o poder derivado dela toma uma forma hegemônica. (VAN DIJK, 2017, p. 47- 48)
}

Isto posto, tendo em vista as afirmações de Van Dijk e os dados obtidos por intermédio da análise aqui apresentada, nota-se que os anúncios de $\mathrm{O}$ Boticário investigados na presente pesquisa colaboram para a manutenção das atuais posições sociais do homem e da mulher no Brasil.

\section{CONSIDERAÇÕES FINAIS}


Sob a perspectiva da Teoria Semiolinguística, o corpus analisado ao longo do presente trabalho indica que as inferências contidas nos anúncios de O Boticário voltados especificamente para os públicos masculino e feminino contribuem para a difusão de imaginários sociodiscursivos de gênero, promovendo, assim, a manutenção de uma compreensão social acerca do que é esperado no Brasil dos comportamentos de homens e mulheres.

Nota-se que em tais propagandas é estimulada a concepção da masculinidade como, resumidamente, detentora dos atributos da força e da determinação, enquanto às mulheres cabem as características da sensualidade, beleza e delicadeza. Desse modo, levando-se em consideração que O Boticário é uma marca muito conhecida e utilizada no país, tais apontamentos indicam as evidências da coincidência da compreensão popular com os imaginários disseminados pelas campanhas da empresa.

\section{Referências}

BAKHTIN, Mikhail. Estética da criação verbal. São Paulo: Martins Fontes, 2011.

BOURDIEU, Pierre. A dominação masculina. Rio de Janeiro: BestBolso, 2018.

CHARAUDEAU, Patrick. "Uma análise semiolinguística do texto e do discurso". In: PAULIUKONIS, Maria Aparecida Lino; GAVAZZI, Sigrid (orgs.). Da língua ao discurso: reflexões para o ensino. Rio de Janeiro: Lucerna, 2007, p. 11- 29.

Discurso político. São Paulo: Contexto, 2015.

Linguagem e discurso: modos de organização. São Paulo: Contexto, 2016.

. Os estereótipos, muito bem. Os imaginários, ainda melhor. In:

Entrepalavras, Fortaleza, v.7, p. 571 -591, jan/jun. 2017.

. Discurso das mídias. São Paulo: Contexto, 2018.

DELL'ISOLA, Regina Lúcia Péret. Leitura: inferências e contexto sociocultural. Belo Horizonte: Formato, 2001.

DIJK, Teun A. Van. Discurso e poder. São Paulo: Contexto, 2017.

MINSKY, Marvin. A framework for representing knowledge, 1974. Disponível em: <http://www.cogsci.ucsd.edu/ coulson/203/minsky.pdf>. Acesso em: 20 de abril de 2019. 
Recebido em: 31/01/2021

Aceito em: 08/05/2021 